\title{
4 Imagination, Metaphysical Modality, and Modal Psychology
}

\author{
Michael Omoge
}

\subsection{Introduction}

We use imagination in many activities: pretense, thought experiments, counterfactual reasoning, modal judgments, and so on. However, in modal judgments notably, there is considerable skepticism about whether imagination can play the required epistemic role. Even here, using imagination to reach conclusions about practical modality (i.e., the kind that features in everyday reasoning) doesn't elicit the same vivacious skepticism as using it to reach conclusions about metaphysical modality (i.e., the kind that features in sophisticated philosophical reasoning) does.

For instance, if I say I can free climb the Yosemite's El Capitan because I have imagined it and it is possible, you probably won't object too much. But if I say something can be water without being $\mathrm{H}_{2} \mathrm{O}$ because I have imagined it and it is possible, you are most likely going to object. In short, using imagination to reach conclusions about metaphysical modality elicits strong skepticism, and most of the views (e.g., Quine (1969); Blackburn (1993); Hill (1997); Van Inwagen (1998); Nichols (2006)) that express skepticism about whether imagination can deliver modal judgments target metaphysical not practical modality. Metaphysical modal judgments, or 'metaphysical modalizing' for short, is the bugbear, and this chapter aims to address this skepticism about it. ${ }^{1}$

Standardly, the approach taken to address the skepticism is often metaphysical $^{2}$ in that the focus is on whether imagination can enable agents to modalize (e.g., Yablo (1993); Chalmers (2002); Gregory (2004); McGinn (2004); Kung (2010)). ${ }^{3}$ The idea is to connect imagination with modality through some conceptual means, e.g., the possible worlds framework. This way, the offered epistemological explanations are often rationalistic in that they are independent of the empirical sciences that study imagination. And rationalism about modalizing seems to be one of the factors that underwrite skepticism about it in the first place. This is because metaphysical modal facts are often (but not always) taken to be mind-independent, and so, it becomes unclear how a mind-dependent 
cognitive faculty like imagination enables agents to modalize (see, e.g., Roca-Royes (2019)).

Instead of this whether-response then, we might give a how-response, i.e., we can focus on how imagination might enable agents to modalize. This sort of response would be psychological in that it focuses on the process underlying our imaginative capacities when used to modalize. Shaun Nichols calls this approach 'modal psychology':

In addition to metaphysical and epistemic questions about modality, there is another question, which is sometimes treated as a shameful relative of the others: What is involved, psychologically, in making modal judgments? That is, in addition to modal metaphysics and modal epistemology, one might study modal psychology.

(2006, 237, original italics)

Thus, the method of modal psychology is naturalistic, in that it is informed by the sciences that study imagination.

Since the widespread skepticism about the usage of imagination to modalize is underwritten in part by rationalistic methods, and since modal epistemology is typically rationalistic, it would help if we step away from modal epistemology, as it is typically done, to modal psychology in our attempt to address this skepticism. That will be how I proceed in what follows. Specifically, I intend to explain what is involved psychologically when we use imagination to modalize. In doing so, I set aside epistemological questions about whether we are justified in relying on imagination in modalizing, or whether imagination has the required epistemic status to be so used.

But though Nichols classifies modal psychology as a different project from modal epistemology, Daniel Nolan suggests that it is a project in 'naturalized modal epistemology':

If our discovery of modal facts is a process not dissimilar to our discovery of other, better understood, ranges of facts, then the investigation of ourselves and our capacities to respond to the world might indirectly shed some light on what we are responding to when we get the modal facts correct.

(2017, 19, my italics)

But why does modal psychology potentially resolve modal epistemological problems 'indirectly'? Because

[m]erely detecting what prompts modal judgments would not settle epistemological questions, but on the assumption that ordinary users of modality are doing a good job [...] investigating how they in 
fact form their judgments should provide us defeasible accounts of what it takes to correctly form those judgments.

(Nolan 2017, 19)

Thus, besides explaining what is involved psychologically when we use imagination to modalize, I want to use the psychological explanation I will develop as part of an effort to give a defeasible account of what it takes for an agent to correctly use their imagination to modalize. In short, I consider my psychological explanation and the defeasible account it affords as offering a way to address the widespread skepticism about the usage of imagination in modalizing. In this way, following Nolan, my project in modal psychology is also a project in naturalized modal epistemology: it seeks to address a modal epistemological question naturalistically.

I should also clarify that although psychologizing a realm of study often implies anti-realism about that realm, I will be agnostic about the metaphysics of metaphysical modality here, and so, my modal psychology shouldn't be read as endorsing modal anti-realism. I would like to think that the psychological processes underlying realists' and antirealists' usages of imagination in modalizing are exactly the same. Describing those processes is my target here. To be safe, therefore, my task here can be taken as this conditional: if imagination does indeed enable agents to metaphysically modalize, then the view I will describe here provides the best way of accounting for this naturalistically.

To give this naturalistic account, I will rely on Nichols and Stich's (2003) cognitive theory of imagination, using it to explain what is involved psychologically when we use imagination to modalize (Section 4.2). Since their theory is speculative, my account too must be speculative, and, hence, might seem overly optimistic. But this isn't just a problem for me; any attempt to psychologize imagination's epistemic role will be speculative-imagination is one of our less understood cognitive faculties, compared to perception, say. Nonetheless, I will address this worry by psychologizing philosophers' disagreements about what is metaphysically possible (Section 4.3). I will argue that by scrutinizing the psychological processes underlying their usages of imagination in modalizing, we can tell who among them is correctly using their imagination to modalize. This way, the account also addresses whatever skepticism might arise from such disagreements.

Thereafter, I will respond to Nichols' (2006) view that rather than providing an answer to the skeptics, modal psychology instead ends up promoting skepticism about the usage of imagination in modalizing, at least in the metaphysical domain ${ }^{5}$ (Section 4.4). I will show how his argument is faulty, and using my arguments in Sections 4.2 and 4.3 as additional premises, I will argue that modal psychology dispels rather than supports such skepticism. 


\subsection{The Psychology of Imagination and Metaphysical Modality}

The cognitive theory of imagination offered by Nichols and Stich focuses on propositional imagination (i.e., imagination as a propositional attitude that's not necessarily imagistic), and I will here follow their lead. They put forth the theory in a bid to explain some practical usages of imagination, like mindreading and pretense. So, their examples involve everyday cases, like a child imagining that a banana is a telephone handset. But since my goal is to explain the metaphysical usage of imagination, I will apply what they say to examples of modalizing cases, like the possibility of phenomenal zombies.

Nichols and Stich build their theory on a standard model of the basic architecture of the mind. The perception/belief/desire architecture is widely accepted among philosophers of mind as a model for almost all animals that possess some sort of central nervous system. For Nichols and Stich, building the architecture of imagination on this basic model requires three additional boxes: an 'imagination box', an 'UpDater', and a 'script elaborator'. Talk of 'boxes' here, the employment of which is often called 'boxology', doesn't imply that representation tokens in a box share a spatial location in the mind, but that they share an important cluster of causal properties which other representation types don't share. Though some philosophers have raised concerns about the fruitfulness of boxology in theorizing about imagination (see, e.g., Stock (2011)), I will follow the boxology approach here.

According to Nichols and Stich, the imagination box is a "workspace in which our cognitive system builds and temporarily stores representations of one or another possible [scenario]" $(2003,28)$. As they explain it, imagination episodes begin with an imagination premise, an arbitrary explicit input that kick-starts imaginative acts. Take the case of phenomenal zombies. The debate is about whether they are conceptually, and, therefore, metaphysically possible. David Chalmers gives the description of a (phenomenal) zombie this way:

The creature is molecule for molecule identical to me, and identical in all the low-level properties postulated by a completed physics, but he lacks conscious experience entirely [...] he is physically identical to me [but] none of this functioning will be accompanied by any real conscious experience. There will be no phenomenal feel. There is nothing it is like to be a zombie.

$(1996,94-5)$

For simplicity's sake, let us take the representation token, there are creatures that are physically identical to us but not conscious, as the imagination premise that kick-starts imaginative episodes about the possibility of zombies. 
Following Nichols and Stich, since the imagination box is the workspace where imaginings are built, this imagination premise would be put inside it. But the imagination premise won't be sufficient to yield the possibility of zombies: depending on one's pre-existing beliefs, many things or nothing could follow from it. Thus, Nichols and Stich say that "in addition to the [imagination] premise, the cognitive system puts [copies of the] entire contents of the belief box into the [imagination] box" $(2003,29)$. This, they say, ensures that there will be enough premises to yield the target imagining. The challenge, however, is that some pre-existing beliefs will most certainly be incompatible with the imagination premise, and so, they may block the target imagining from forming. Nichols and Stich say that the UpDater ensures that this doesn't happen.

The UpDater's job, according to them, is to filter out pre-existing beliefs that are incompatible with the imagination premise. For instance, getting to the possibility of zombies from the combination of the imagination premise (there are creatures that are physically identical to us but not conscious) and one's pre-existing beliefs would require revising some nomological beliefs about rationality. Perhaps one might have to be flexible about rationality, and that would require revising the belief that 'consciousness is indispensable to rationality'. Likewise, if one wants to imagine physically impossible but metaphysically possible objects, many pre-existing beliefs about mass, gravity, and so on might have to be revised-impossible objects may just lack any known physical property altogether.

Without the UpDater then, our inference mechanisms won't have the relevant and appropriate premises (the imagination premise and the UpDater-filtered beliefs) to work with, in which case, our target imaginings mightn't form. But often, we imagine very rich, detailed, and fantastical things for which it would be farfetched to say our pre-existing beliefs are sufficient as the required premises. For instance, I might imagine a zombie world alongside imagining the possibility of zombies, i.e., I might not just imagine individuals who lack consciousness in worlds like ours, but also imagine worlds very much unlike ours by virtue of lacking consciousness altogether. ${ }^{6}$ And it is very much possible that my pre-existing beliefs might not be able to get me all the way to imagining zombie worlds, even though they got me to imagining zombie individuals-modalizing involves intuitions that cannot be explained solely in terms of pre-existing beliefs. The natural question that comes to mind then is where the non-inferable details come from. Nichols and Stich's answer is that they are supplied by the script elaborator.

The script elaborator works to fill "in those details of [an imagination episode] that can't be inferred from the [imagination] premise, the UpDater-filtered contents of the belief box and the [imaginer's] knowledge of what has happened earlier on in the [imagination]" $(2003,35)$. 
But how does the script elaborator achieve this task? Here, Nichols and Stich bring in the notion of scripts from cognitive psychology (Schank and Abelson (1977); Abelson (1981)). According to Schank and Abelson, "a script is a structure that describes appropriate sequences of events in a particular context" $(1977,41)$. A script, they say, is generated for an event on account of the event's repeatedness; e.g., by repeatedly going to restaurants, a restaurant script is generated. ${ }^{7}$

Initially, Schank and Abelson take scripts to explain how we act in a given scenario: your restaurant script is at work when you entered a restaurant, went through the routine, without much thought. But later, Abelson adds that there are scripts that guide how we understand a given scenario: "Scripts play a double role in psychology. There are scripts in understanding and scripts in behavior" $(1981,719)$. If I frequent Moroccan restaurants but you don't, and so, I am acquainted with Moroccan eating etiquette, then I might be able to make sense of this short story and you mightn't: "Seun went to a Moroccan restaurant, and after washing his hands, he left". For you might ask: "Why didn't he eat, why did he just wash his hands and leave?" Simply, your imagination is limited because your restaurant script isn't as detailed as mine. It is part of Moroccan etiquette to eat with hands, and just by hearing that Seun left after washing his hands, I can fill in the gaps-that he already ate. Thus, a restaurant script can be a behavior script or an understanding script, depending on the imaginer's goal.

Another way to explain this story is to say that due to my frequenting Moroccan restaurants, I now have a restaurant script specifically for Moroccan restaurants-a Moroccan-restaurant script, say-but you just have a (generic) restaurant script. The Moroccan-restaurant script is, therefore, a more detailed restaurant script. Notice, however, that even though the Moroccan-restaurant script is an understanding script in the story, a behavior script is implicit in it: were there no script for how people behave in Moroccan restaurants, even I would not be able to understand the story.

Since the goal in modalizing is to understand modal scenarios, there are understanding scripts that detail how modal scenarios typically unfold. Let's call them 'modalizing scripts'. ${ }^{8}$ For example, to imagine whether zombies are possible, the relevant modalizing script (call it, a zombie script) is that which details how thoughts involving 'consciousness' typically unfold. Thus, just as the Moroccan-restaurant script is a more detailed restaurant script, the zombie script is a more detailed modalizing script, one that's generated when an agent repeatedly uses their modalizing script to make sense of whether zombies are possible. So, Chalmers, say, would have a zombie script, whereas a freshman philosophy student would have only a modalizing script, i.e., where Chalmers can skip many steps when modalizing about zombies, the freshman 
mightn't be able to. In addition, the zombie case (and arguably many others) is like the above story, i.e., a behavior script is implicit in it: were there no script for how humans, a fortiori, zombies behave, no modalizing script would work for understanding whether zombies are possible. More on this in Section 4.3.

In my view, scripts play a much larger role in imagining, a fortiori in modalizing, than Nichols and Stich reckon. Not only can their operation explain where details that aren't inferable from pre-existing beliefs and the imagination premise come from, as Nichols and Stich say, scripts can also inform prescribing the correct usage of imagination. More on this also in Section 4.3.

What then do Nichols and Stich say about how scripts enable the script elaborator to supply those non-inferable details? They argue, first, that scripts supply some of the details by supplying intuitions that aren't produced by explicit reasoning in imagination. They say 'some' because scripts are non-restrictive, in that we can deviate from them and imagine what they couldn't inform. I could also imagine that Seun stood while eating, and this wouldn't be informed by my Moroccan-restaurant script, since it is part of Moroccan etiquette to eat while sitting on mats. I can imagine whatever I want. So, Nichols and Stich argue, second, that there must be a mechanism, which teases deviations out from scripts, and they take these deviations to be the details that are left which scripts do not supply. Hence, the script elaborator. Thus, with my zombie script, my script elaborator will be able to tease out any other details, which are neither supplied by scripts nor inferable from the combination of the imagination premise and my pre-existing beliefs.

This, it seems to me, is a plausible description of how imagination yields the modalizing episode that zombies and zombie worlds are possible. Simply, we can explain how imagination enables agents to have metaphysical modal judgments (i.e., modalize) through modal psychology.

As things stand, why a philosopher and a physicist, say, might have fundamentally different imaginative contents about the possibility of zombies seems clear enough. Given the same imagination premise (there are creatures that are physically identical to us but not conscious), the philosopher might get to the possibility of 'phenomenal' zombies, and the physicist, to the kind of zombies depicted in Hollywood movies, which Chalmers $(1996,95)$ calls 'psychological' zombies. Simply, the philosopher's zombie script has more details than the physicist's, if they are even using the same modalizing script. But the current analysis won't work for why two philosophers disagree about the possibility of (phenomenal) zombies, since they presumably have equally detailed zombie scripts. And this seems to be a general fact about modalizing: philosophers often have equally detailed modalizing scripts and still disagree about whether the given modal scenario is possible. What then? 


\subsection{The Psychology of Imagination and Disagreements about Metaphysical Modality}

Talk of having more detailed scripts implies that what is imaginable is a function of domain-specific knowledge. If I have more domain-specific knowledge than you in a given area, then the content of my imagination in the area will be richer than yours. I could but you couldn't imagine that Seun had eaten because my domain-specific knowledge about Moroccan etiquette is more than yours. Mutatis mutandis for the philosopher and the physicist with regard to the zombie script. But two disagreeing philosophers presumably have equal domain-specific knowledge about a modal scenario. Shoemaker (1999), who denies the possibility of zombies, presumably has equal domain-specific knowledge in metaphysics and logic as Chalmers (1996), who countenances their possibility. Why then do they disagree if their zombie scripts are presumably equally detailed? Do such disagreements not give weight to the widespread skepticism about the usage of imagination in modalizing?

One way of explaining the disagreements that ensue from the usage of imagination in modalizing comes to us from the independent discussions of Hawthorne (2002), Stalnaker (2002), and Braddon-Mitchell (2003) on the mind-body debate, which seem to suggest that much about the disagreements is semantic. The coherence of this semantic view is debatable, but it nonetheless represents what is, so far, a useful way of thinking about disagreements in modalizing. I will discuss Stalnaker's version here. ${ }^{9}$

According to him, the disagreement between Chalmers and Shoemaker about the possibility of zombies arises because they disagree about what kind of world we live in. Chalmers says we live in a world where some properties, namely, phenomenal consciousness properties don't supervene on the physical: for him, consciousness is irreducibly nonphysical. Shoemaker disagrees: for him, consciousness is physical/behavioral/ functional, and so, whatever phenomenal consciousness properties there could be in our world are already part of the subvenients.

Stalnaker's move (or, as Lycan (2007) explains him) then is this. We are phenomenally conscious, but we can't tell in which world we are so: Chalmers' or Shoemaker's. So, Chalmers isn't entitled to say 'zombies are imaginable', since that turns on us being phenomenally conscious in a Chalmersian world, i.e., in a world where phenomenal consciousness properties fail to supervene on the physical. Since Shoemaker denies this, he isn't wrong then on semantic grounds that 'zombies are unimaginable'. Thus, Stalnaker concludes:

The issue concerns how theoretically loaded the idea of phenomenal consciousness is [...] it seems clear that [Chalmers is] building some 
theoretical content into the concept of phenomenal consciousness [Shoemaker] uses the word 'consciousness' in a contrasting way, but a way that may also be theoretically loaded.

$(2002,391 \& 393-4)$

If so, then we can generalize: much about disagreements in modalizing is semantic, because the disagreements turn on how theoretically loaded relevant key concepts are.

It might be said, however, that if this is true, then modalizing itself becomes an untrustworthy process, since philosophers have always been engaging in this sort of disagreements through modalizing, thereby treating the disagreements as substantive not merely semantic. I think this challenge works only if the disagreements are entirely semantic, which they aren't. Lycan clarifies: "Stalnaker does not hold that the entire mind-body issue is semantic, because the dualist and the materialist disagree over [what kind of world] we live in" $(2007,475)$. If so, then it doesn't automatically follow that modalizing becomes untrustworthy, for the non-semantic, a fortiori substantive, aspect of the disagreements might be underlaying philosophers' engagements in them via modalizing all these years. What substantive aspect?

Stalnaker is clear. The mind-body issue divides into two subdisagreements: whether (a) we live in a zombie world, and (b) zombie worlds are possible. Where (a) is factual-neuroscience can settle itand so substantive, (b) is semantic-we can't take an intergalactic space shuttle to zombie worlds to settle it. Since (a) is substantive, the relevant question, then, is whether it has always been underlaying philosophers' engagements in the mind-body debate via modalizing, such that it gives some legitimacy to modalizing. I think it does.

It is our attempt to answer the question of what kind of world we live in that led philosophers to postulate zombie worlds through modalizingthis, I take it, is why some of the best modal epistemologies were given in a bid to clarify issues in metaphysics and philosophy of mind (see Section 4.1, esp. n. 2). Simply, modalizing is inevitable if metaphysics is to deliver on its promise of unraveling the fundamental structure of the world (see, e.g., Lowe (2011)).

With this epistemological challenge out of the way, let us return to our psychological analysis. As we have seen, Stalnaker's reason for saying that much about disagreements in modalizing is semantic is that the disagreements are fueled by the theoretical baggage with which philosophers modalize. This gives us a promising link to the picture I have been painting about the psychological process underlying the usage of imagination in modalizing. Precisely, we have a link that connects us to scripts. Scripts, recall, are psychological paradigms that detail how repeated events typically unfold. What is relevant about them now is how they are activated. 
Schank and Abelson say:

To define when a script should be called into play, script headers are necessary. The headers for the restaurant script are concepts having to do with hunger, restaurants, and so on in the context of a plan for action for getting fed [...] The rules for activating a script are dependent on certain key concepts or conceptualizations when found in certain context.

(1977, $46 \& 48$, my italics)

Scripts are activated conceptually. Hence, I could imagine that Seun had eaten just by hearing 'Moroccan restaurant' in the relevant context.

Schank and Abelson also note that "a script must be written from one's particular role's point of view. A customer sees a restaurant one way, and a cook sees it another way" (1977, 42, my italics). In other words, different restaurant scripts are activated for the cook and the customer, although the scripts share common headers/key concepts. I explained earlier (Section 4.2) that Schank and Abelson initially conceive scripts as behavior scripts; hence, their limiting what informs the cook's and the customer's points of view to the role they play in restaurant scenarios. I then explained that Abelson later adds that there are also understanding scripts. So, when the restaurant scripts are understanding scripts, what is informing the cook's and the customer's points of view would be their domain-specific knowledge- the customer might be a food blogger, and so, her perspective on issues about restaurants will differ from the cook's. In short, while sociological differences usually lead to different behavior scripts, theoretical differences usually lead to different understanding scripts.

Since modalizing scripts are understanding scripts, and since disagreements in modalizing turn on the theoretical load of key concepts, different modalizing scripts will be activated for the disagreeing philosophers. For their points of view will be different since they are building different theoretical contents into, or applying different theoretical interpretations to, the same concepts. We shall see what this amounts to, shortly. For now, it suffices that Chalmers' zombie script will be different from Shoemaker's, although sharing key concepts. Since scripts guide the unfolding of imaginative events, different events will then be unfolded for them: for Chalmers, the possibility of zombies, but for Shoemaker, their impossibility. ${ }^{10}$

Thus, to answer the first question we began this section with: even though their zombie scripts are presumably equally detailed, philosophers disagree about the possibility of zombies because their zombie scripts are different, thanks to their different theoretical baggage with which they modalize. This doesn't mean that they just recycle their existing views when they modalize, however. For not only is imagination a form of reasoning (see Myers, this volume), it is clear from Section 4.2 that many inferences occur in modalizing, and so, new views are reached. 
What about the second question? Given that disagreements in modalizing boil down to the disagreeing philosophers using different but presumably equally detailed modalizing scripts, doesn't this add to why we should question the reliability of imagination when so used? No. I will extend the ongoing analysis to offer one way of resolving this residual skepticism.

Earlier I said scripts generate on account of events' repeatedness (Section 4.2), but that was an oversimplification. Actually, what Schank and Abelson say is that for scripts to generate, events must be repeated in a (or rather, the same) sequence. You have a restaurant script because you repeatedly went to restaurants where you always ordered before you could eat.

If so, then we can say more about the generation of scripts if we know what determines events' sequences. Since events can be physical or mental, candidates would include perception and introspection: by repeatedly going to restaurants, a restaurant script is generated; by repeatedly thinking about zombies, a zombie script is generated. This then means that scripts can be compositional, i.e., two perceptually and/or introspectively formed scripts might be activated concurrently and sometimes (but not always) compose a new one. From my Moroccan-restaurant script and my script for singing karaoke, my cognitive system can generate a script for singing karaoke at Moroccan restaurants. It stands to reason that all modalizing scripts are compositional, and that some of them have behavior scripts as part of their components. Hence, I said earlier (Section 4.2) that behavior scripts are implicit in some modalizing scripts, and I gave the zombie script as an example. Let me now explain further.

Chalmers thinks human actions are decomposable into phenomenal and functional descriptions, such that only the latter applies to zombies whereas both apply to us. Shoemaker disagrees: for him, human actions are inextricably both phenomenal and functional, and so, there can't be zombies because that would mean we are zombies too, which we aren't. Both Chalmers' and Shoemaker's zombie scripts thus have, as components, the behavior script for phenomenal actions and the behavior script for functional actions. Hence, as I said in Section 4.2, were there no scripts for how humans behave, there won't be zombie scripts. ${ }^{11}$

If so, then we can explain how zombies are seen as possible for Chalmers but impossible for Shoemaker. Given the manner in which their zombie scripts are composed, which divides into at least two behavior scripts for Chalmers but one for Shoemaker, the imaginative event unfolds in two ways for Chalmers, such that one leads to the possibility of zombies; whereas, it unfolds in only one way for Shoemaker, and that way rules out the possibility of zombies. Simply, for compositional scripts, the manner of composition plays a big role. Another such role is informing a prescription of the correct usage of imagination. 
When scripts are compositional, there are often interferences, i.e., "states or actions which prevent the normal continuation of a script" (Schank and Abelson 1977, 52). Since interferences surface during the unfolding/elaboration of scripts, possible candidates are few. For instance, instructions like 'suppose you were in a restaurant but there was no food', which conflicts with the normal unfolding of your restaurant script, drop out; they are rather the imagination premises on such occasions, since they are invitations for you to imagine. A good example of interferences, at least for understanding scripts, are propositional states that do not directly mesh with the agent's domainspecific knowledge. Importantly, Schank and Abelson use 'interference' normatively, in that they take interfering with (imaginative) goals as something bad. I will follow suit here. With interferences thus understood, we can give some prescriptions about the usage of imagination in modalizing.

First, we have seen that stages in scripts are sequential, but that's not all. Abelson adds that what matters is that the stages be connected causally. It is true that ordering a meal precedes eating it, but what matters is that in order to eat a meal in a restaurant, one must have ordered it. The former causally enables the latter to unfold: "The distinctive aspect of scripts is the relevance of learned associations between prior and consequent events. These associations are usually meaningful rather than rote because of causal 'enablements' between script events" (1981, 717). Now, suppose that during the composition of their zombie scripts, there were interferences for Chalmers but not Shoemaker. Further suppose that the interferences blocked the causal enablements between the stages of Chalmers' phenomenal-action and functional-action scripts. Perhaps they blocked how phenomenal consciousness properties fail to supervene on the physical, such that he reached the conclusion that we live in a zombie world illicitly. Since such causal enablements are supposed to ground the composition of his zombie script in the first place, the imaginative event that was unfolded for him would be problematic. The details his script elaborator supplied would be defective, and so, what it takes for him to correctly use imagination to modalize is hampered. Simply, he would be wrongly using imagination to modalize. Mutatis mutandis for Shoemaker.

Second, Abelson adds:

[E]vents in scripts differ in their centrality to the action flow; some events are indispensable to the script and summarize scenes consisting of lower level actions. 'Ordering the meal' and 'eating the meal', for example, are more central than are, say, 'discussing the menu' and 'lifting the fork'. 
Given what Stalnaker $(2002,388$, n. 1) says, "whether the actual world is a zombie world" is more central to the zombie script than "whether there could be two discernible possible worlds fitting the description of a zombie world", or "whether there could be physical laws that permit the emergence of nonphysical phenomena". Now suppose that both Chalmers' and Shoemaker's zombie scripts have interferences, but that while the interferences are blocking the latter less central stages of Chalmers' zombie script, they are blocking the former more central stage in Shoemaker's. It would follow that the supplied script-elaborated details for Shoemaker would be much more defective than those supplied for Chalmers, and so, Chalmers would be correctly using imagination to modalize more than Stalnaker. Again, this works the other way around.

Nonetheless, interferences are typically easily correctable. A waiter who brings you a burger after you ordered chicken wings, though interfering with the unfolding of your restaurant script, can easily be reminded about the correct order, and your restaurant script will continue to unfold normally. But not so for modalizing scripts. Due to the peculiar theoretical load of their key concepts, interferences often go unnoticed, and so, they aren't easily correctable. This is what the theoretical load amounts to, and it explains why the ensuing disagreements run very deep. I, for one, am in Chalmers' camp, but I could be wrongly using imagination to modalize, in that some interferences might be preventing the normal unfolding of my zombie script. Even now that I can see how this could be the case, I am no less convinced that my imagination leads me to the possibility of zombies. My view about the possibility of zombies and my usage of imagination to reach the view come apart. After all, if I am not using imagination to modalize but, say, I am using counterfactual reasoning, ${ }^{12}$ the ongoing psychological analysis mightn't work-what is involved psychologically in imagination and counterfactual reasoning are most likely nonidentical.

To be clear then, the analysis here isn't about my or Chalmers' or Shoemaker's or any philosopher's view on the mind-body (or any other metaphysical modal) debate, but about the usage of imagination to reach such views. Although 'whether the views are correct' and 'whether imagination is correctly used to reach them' are both epistemological questions, the former requires a metaphysical account, whereas the latter requires a psychological one (see Section 4.1). So, to reemphasize, 'correctly use', as I've been using it, qualifies imagining not modalizing. ${ }^{13}$

The crucial point, then, is that by taking a closer look at the psychology of imagination, one way of addressing whatever skepticism about the usage of imagination in modalizing that might arise from disagreements in modalizing opens up. If we shift our focus to scripts, we can tell who, between the disagreeing philosophers, is correctly using their imagination (i.e., in accordance with an interference-free modalizing 
script) to modalize. If so, then the psychological account here offered sheds any exaggerated optimism it could be said to have. For it no longer just explains how imaginability yields possibility as with Chalmers, it also explains how it might yield impossibility as with Shoemaker, why it can go either or both ways, and how to tell who is correctly using their imagination to modalize when it does go both ways. Thus, even though the account is speculative, it caters for some of the necessary aspects of modalizing, ${ }^{14}$ and so, it is a step in the right direction, at least relative to naturalistic concerns. Simply, much of the skepticism about the usage of imagination in modalizing can be addressed through modal psychology.

\subsection{Can We Really Psychologize Metaphysical Modality?}

Nichols (2006) raises one potential problem for this (and any) sort of imagination-based psychological analysis of metaphysical modality. According to him, specifying the architecture of imagination makes it clear that imagination is reliable only when used for practical not metaphysical modalizing:

[I]f the modal psychology sketched here is right, it might contribute to a skeptical view about the epistemic status of imagination-driven intuitions of absolute modality. Given certain widely shared assumptions, like the assumption that the future will resemble the past, it's plausible that the imagination provides a good guide to risk and opportunity. That's in part what it's designed to do. However, when this imaginative capacity is appropriated in the service of judgments of absolute possibility and necessity, it's less clear that we can trust the verdicts. For here the psychological systems are being used outside their natural domain. Hence, there's less reason to think that they will be successful guides in this foreign terrain of absolute modality.

(2006, 253)

As Sections 4.2 and 4.3 show, I began from the same psychological perspective as Nichols- he too relies on Nichols and Stich (2003). But unlike him, I arrived at a view that does not further promote skepticism about the usage of imagination to metaphysically modalize but rather helps to dispel it. What accounts for this difference?

I will argue that his view that modal psychology supports skepticism relies on a faulty premise:

(P) The reliability of a cognitive capacity, when used for a certain purpose, depends on the functions the capacity evolved to perform. ${ }^{15}$ 
The goal is for the debunking argument I will give here to corroborate the vindicating one I've given in Sections 4.2 and 4.3. In what follows, the argumentative tone will differ from what has come before-still psychological, but more evolutionary than cognitive.

The truth is this: we use many cognitive capacities outside their natural domain, and we don't start distrusting their verdicts when they are used in those unnatural domains. Consider geometric reasoning. It is generally regarded as the product of some basic spatial cognitive capacity, like the one that facilitates our ducking to avoid bumping our heads, reaching for objects at a distance, and so on. Mateusz Hohol and Marcin Miłkowski put it better: an account of geometric reasoning "should recognize 'hardwired,' or evolutionarily early, cognitive abilities that are necessary to engage in Euclidean geometry, such as natural sensitivity to distance (proximal-distal), sense (left-right) and angle, and thus explain where geometric cognition comes from" $(2019,4)$.

Even though geometry is an elaborated development of a function of spatial capacity, and even though it evidently wasn't what the capacity evolved to perform, that doesn't entitle us to start distrusting it. Geometry has been, is, and will continue to be very important to our understanding of the universe. In fact, some other sophisticated aspects of our life, like architecture and space-traveling, would become unworkable without it. It is just absurd to say that because spatial capacity evolved only to stop us from banging our heads on the tops of caves, we should have distrusted its verdicts when we started to use it for geometric reasoning.

Our spatial capacity already got us into the geometry game, and even though the elementary geometry-ish things we were able to do with it, like cutting the distance between three L-shaped points by walking diagonally from one end of the L to the other, weren't guaranteed to be right, we have disciplined them to such a degree that we can now do things that spatial reasoning could never do. From walking to cut distances between three L-shaped points, we have constructed the idea of triangles, and from there to quadratic equations, trigonometry, Pythagoras' theorem, and so on. And it is highly doubtful that we would have arrived here had we not begun to use spatial capacity for geometric reasoning in addition to spatial reasoning.

The point here is that the close relationship between practical and metaphysical modalizing as the natural and unnatural usages of imagination can be akin to the one between spatial and geometric reasoning as the natural and unnatural usages of spatial capacity. Imagination already got us to practically oriented modalizing, such that getting from there to metaphysically modalizing didn't require evolving a separate capacity-this, I take it, is why it is common practice to begin discussions of metaphysical modality from practical modality (see n. 3). If so, then we shouldn't distrust metaphysical modalizing just as we 
didn't distrust geometry, since they are both unnatural usages of their respective capacities.

Nichols might respond, however, that before we trust a given capacity in a new employment, we need some positive reason to think it is trustworthy. For instance, demonstrated success, which geometry has but metaphysical modalizing lacks. Also, evolutionary usefulness, which favors practical but not metaphysical modalizing. The idea here is that if we evolved a particular capacity, then presumably the functions it performed that got it selected was useful, or at the least, its selection was a function of demonstrated success. What then?

Consider our capacity for sugar detection, which subserves detecting which food is rich in fructose and its ilk, and which food lacks them completely. While the former is basic, the latter is an add-on. Evidence abounds that we only initially evolved to detect sugar; detecting sugarless foods evolved much later when the former starts to be maladaptive as diabetes surfaced (e.g., Watve and Yajnik (2007)). Detecting sugarless food is a positive not negative function, and so, it requires action not inaction from the sugar detector (cf. Millikan 1984, esp. ch. 14). After all, there is a whole lot of biological connections that went into evolving detecting sugar-rich foods, which informs the thought that detecting sugarless foods would also require its own biological connections, or at least some modifications of existing ones, and so, it evolved later than detecting sugar-rich foods. ${ }^{16}$

Nonetheless, at the current stage in our evolutionary history, it is clear that if the sugar detector fails to deliver the whole package, we die off: sometimes, what we need isn't more sugar but less and even no sugar at all. Now, geometry and metaphysical modalizing aren't like this: we certainly won't die if we couldn't reason geometrically or metaphysically modalize. They are add-ons, which spatial capacity and imagination, respectively, need not deliver. Thus, the fact that geometry but not metaphysical modalizing has demonstrated success counts for less in judging whether we should trust either or both of them. What matters is that there was no selective pressure for the relevant capacity to deliver them, and so, they stand or fall together. Demonstrated success, therefore, fails to explain why we evolved using spatial capacity for geometric reasoning and imagination for metaphysical modalizing. In both cases, demonstrated success is post facto.

If so, then how to determine the usefulness of a capacity's functions becomes unclear. No doubt, practical modalizing (like geometry) has empirical usefulness, which differentiates it from metaphysical modalizing. But this can no longer be the reason metaphysical modalizing is untrustworthy. What we need is a reason why practical modalizing's empirical usefulness renders it trustworthy, and metaphysical modalizing's theoretical usefulness renders it untrustworthy. So, pointing to 
empiricality as the reason practical modalizing but not metaphysical modalizing is trustworthy becomes question-begging.

Moreover, it isn't even entirely true that metaphysical modalizing is only theoretically useful. Matteo Morganti puts it this way: "metaphysical conjectures and theories can turn into empirically relevant theses-at least in the sense that they become indirectly testable, i.e., relevant for the interpretation of science, at specific junctures in the history of science (and philosophy)" (2015, 62). Thus, in some sense, metaphysical modalizing is also empirically useful, such that even if there is a way in which it isn't question-begging and empiricality is the determinant factor for the usefulness of a capacity's functions, then trusting practical modalizing but not metaphysical modalizing on the basis of empirical usefulness becomes arbitrary.

In short, the original evolutionary functions of a capacity aren't as significant in appraising the capacity's verdicts when used for a newly evolved function, as Nichols might think. Certainly, our capacity to use imagination to metaphysically modalize evolved much later, perhaps with the evolution of logical reasoning, ${ }^{17}$ and we have already begun to use imagination to practically modalize by then, but that doesn't mean imagination becomes unreliable when we now start to use it to metaphysically modalize. Timothy Williamson puts it summarily:

The cognitive view of the imagination does not predict that it will be cognitively reliable only for tasks just like those it evolved to serve [...] Whatever the function or evolutionary origin of our capacities, we are not forbidden to use them for other ends.

$(2016,121)$

Although, like Williamson, I haven't shown that reliability is sustained in this co-optation, ${ }^{18}$ it suffices that reliability isn't also lost, which is what Nichols is saying. Simply, $(\mathrm{P})$ is false, and so, Nichols' view that builds on it falls apart. Modal psychology doesn't “contribute to a skeptical view about the epistemic status of imagination-driven intuitions of [metaphysical] modality" (Nichols 2006, 253); nothing stands in the way of addressing such skepticism. I have offered one way that modal psychology does this in Sections 4.2 and 4.3. What we have here, then, is both vindicating and debunking arguments that even though modal psychology "does hold promise for partly constraining the theoretical space" (Nichols 2006, 253), it does so in a way that dispels rather than support skepticism about the usage of imagination in metaphysically modalizing.

In so doing, my modal psychology responds to the demand for naturalizing how imagination enables agents to metaphysically modalize, which its rationalistic counterparts fail to apprehend as one important 
factor that underwrites skepticism about using imagination in such a way. It does so by appropriating what was originally designed for practical modality for metaphysical modality, thereby removing any charge of exceptionalism. The psychological process underlying our usage of imagination is, by and large, the same for both practical and metaphysical modalizing. Modal psychology bears fruit in the philosophy of metaphysical modality. ${ }^{19}$

\section{Notes}

1 Unless otherwise stated, when I just say 'modalizing' hereafter, I mean metaphysical modalizing.

2 Hence, Fischer and Leon (2017) point out that, until recently, modal epistemology was done concurrently with metaphysics and philosophy of mind.

3 The approach taken here is usually to show, first, that modalizing in general is a trustworthy process through practical modalizing, and then, second, that metaphysical modalizing is a standard application thereof. But, as I've said, only a few modal skeptics are against practical modalizing and/or modalizing in general; their skepticism often targets metaphysical modalizing specifically. At any rate, while this approach is a viable option, I will isolate metaphysical modalizing here.

4 He gives two other lines of inquiry: the study of (i) the behavior of modal expressions in natural languages, and (ii) the roles modal claims/commitments play in our best scientific theories. Thus, naturalized modal epistemology isn't always psychological.

5 Although Nichols talks in terms of 'absolute modality', I take it that at least some metaphysical modalities (e.g., arithmetical ones) are absolute (cf. Hale 2012). Since his examples are arithmetical cases, I am therefore licensed to talk about him in terms of metaphysical modality.

6 Explicating what imagining zombie worlds amounts to exactly is, however, a difficult and general problem. For it seems to require that one's imaginative perspective is not part of the imagined world, which then makes it difficult to see how one can have such imagining in the first place.

7 It might be said, however, that scripts are unnecessary even for repeated events, since we are almost always engaging in active inferences (Kintsch and van Dijk 1975). See Abelson (1981) for a response to this challenge.

8 Not to be confused with scripts for modalizing, which are behavior scripts. Scripts for modalizing would encode information like "when people are modalizing, they often close their eyes or look off into the distance; they furrow their brow if they are having trouble with something; and so on." They tell us how people behave when they modalize.

9 Although Stalnaker doesn't name Chalmers and Shoemaker explicitly-he uses fictional characters-I will speak in terms of the real-life philosophers.

10 Here, I am taking it for granted that 'the possibility of a scenario' is a thought, and that thoughts are mental events (see Sellars 1981).

11 It might be said that the component scripts aren't behavior but understanding scripts. Fine, but that just pushes my point one step back. For were there no scripts for how humans behave, there wouldn't be any script for understanding the phenomenal and functional aspects of human behaviors, and ultimately, no zombie scripts.

12 See, e.g., Williamson (2007) for a rationalistic account of how counterfactual reasoning is a guide to possibility. 
13 Although one can infer correct or incorrect modalizing from correct or incorrect imagining, I am not making that inference here. To make such an inference, a process-reliabilist account of imaginative modal justification is required, which I have no space for now. See n. 14 .

14 There are other important aspects I haven't addressed here, but which can be potentially addressed through modal psychology as well; e.g., how imagination provides justification for metaphysical modal beliefs.

15 It might be said that I have set up a straw with (P), since it reminds us of 'exaptation', i.e., the process by which a trait previously shaped by natural selection for a particular function is co-opted for another use (Gould and Vrba 1982), which Nichols (see, e.g., page 64 of his 2003 work) is aware of. But given his statement that's quoted above, there seems to be no better way to parse his talk of "designed to do" and "being appropriated in service of" than $(\mathrm{P})$. Thus, to be fair to him, my arguments against $(\mathrm{P})$ won't rely on the seemingly uncontroversial truth of exaptation, even though they can be shortened by doing so.

16 Thanks to Peter Godfrey-Smith here.

17 See Woleński (2016) for an account of the evolution of logical reasoning.

18 Again (as in ns. 13 and 14), to show this, a process-reliabilist account of imaginative modal justification is required.

19 An earlier version of this chapter was presented at the Philosophical Society of Southern Africa Conference in Durban, South Africa. A significantly improved version was presented at the Fiction, Imagination, and Epistemology Conference in Bochum, Germany. The feedbacks from those presentations helped to clarify many parts of the chapter. I thank David Spurrett, Monique Whitaker, Adriano Palma, and Jacek Brzozowski for reading earlier drafts and providing numerous valuable comments. I specially thank Christopher Badura, Amy Kind, and an anonymous referee, whose comments and suggestions are so insightful that they have often been directly incorporated into the text.

\section{References}

Abelson, Robert. 1981. "Psychological Status of the Script Concept." American Psychologist 36(7): 715-29.

Blackburn, Simon. 1993. Essays in Quasi-Realism. Oxford: Oxford University Press.

Braddon-Mitchell, David. 2003. "Qualia and Analytical Conditionals.” Journal of Philosophy 100: 111-35.

Chalmers, David. 1996. The Conscious Mind. Oxford: Oxford University Press. . 2002. "Does Conceivability Entail Possibility?" In Conceivability and Possibility, edited by Tamar Gendler and John Hawthorne, 145-200. Oxford: Oxford University Press.

Fischer, Bob, and Felipe Leon. 2017. “Introduction.” In Modal Epistemology after Rationalism, edited by Bob Fischer and Felipe Leon, 1-6. Cham: Springer.

Gould, Stephen, and Elisabeth Vrba. 1982. "Exaptation-A Missing Term in the Science of Form." Paleobiology 8(1): 4-15.

Gregory, Dominic. 2004. "Imagining Possibilities." Philosophy and Phenomenological Research 69(2): 327-48.

Hale, Bob. 2012. "What is Absolute Necessity?” Philosophia Scientice 16(2): 117-48. 
Hawthorne, John. 2002. “Advice for Physicalists.” Philosophical Studies 108: 17-52.

Hill, Christopher. 1997. "Imaginability, Conceivability, Possibility, and the Mind-Body Problem.” Philosophical Studies 84: 61-85.

Hohol, Mateusz, and Marcin Miłkowski. 2019. "Cognitive Artifacts for Geometric Reasoning." Foundation Science 24: 657-80.

Kintsch, Walter, and Teun van Dijk. 1975. "Toward a Model of Text Comprehension and Production." Psychological Review 85: 363-94.

Kung, Peter. 2010. "Imagining as a Guide to Possibility." Philosophy and Phenomenological Research 81: 620-63.

Lowe, Jonathan. 2011. "The Rationality of Metaphysics." Synthese 178: 99-109.

Lycan, William. 2007. "Stalnaker on Zombies.” Philosophical Studies 133(3): 473-9.

McGinn, Colin. 2004. Mindsight: Image, Dream, Meaning. Cambridge: Harvard University Press.

Millikan, Ruth. 1984. Language, Thoughts, and Other Biological Concepts. Cambridge: MIT Press.

Morganti, Matteo. 2015. "Science-based Metaphysics: On Some Recent Anti-metaphysical Claims”. Philosophia Scientice 19(1): 57-70.

Nichols, Shaun. 2006. "Imaginative Blocks and Impossibility: An Essay in Modal Psychology." In The Architecture of Imagination, edited by Shaun Nichols, 237-55. Oxford: Oxford University Press.

Nichols, Shaun, and Stephen Stich. 2003. Mindreading. Oxford: Oxford University Press.

Nolan, Daniel. 2017. "Naturalized Modal Epistemology.” In Modal Epistemology after Rationalism, edited by Bob Fischer and Felipe Leon, 7-28. Cham: Springer.

Quine, Willard. 1969. Ontological Relativity and Other Essays. New York: Columbia University Press.

Roca-Royes, Sonia. 2019. “The Integration Challenge." In The Routledge Handbook of Modality, edited by Otavio Bueno and Scott Shalkowski. Oxford: Oxford University Press.

Schank, Roger, and Robert Abelson. 1977. Scripts, Plans, Goals, and Understanding. Mahwah: L. Erlbaum Associates.

Sellars, Wilfred. 1981. "Mental Events.” Philosophical Studies 39(4): 325-45.

Shoemaker, Sydney. 1999. "On David Chalmers' The Conscious Mind.” Philosophy and Phenomenological Research 59(2): 439-44.

Stalnaker, Robert. 2002. "What is it Like to be a Zombie?" In Conceivability and Possibility, edited by Tamar Gendler and John Hawthorne, 385-400. Oxford: Oxford University Press.

Stock, Kathleen. 2011. "Unpacking the Boxes." In The Aesthetic Mind, edited by Elisabeth Schellekens and Peter Goldie, 268-82. New York: Oxford University Press.

Van Inwagen, Peter. 1998. "Modal Epistemology.” Philosophical Studies 92: 67-84.

Watve, Milind, and Chittaranjan Yajnik. 2007. "Evolutionary Origins of Insulin Resistance: A Behavioral Switch Hypothesis.” BMC Evolutionary Biology 7(61): https://doi.org/10.1186/1471-2148-7-61 
Williamson, Timothy. 2007. "Philosophical Knowledge and Knowledge of Counterfactuals.” Grazer Philosophiche Studien 74: 89-123.

- 2016. "Knowing by Imagining." In Knowledge through Imagining, edited by Amy Kind and Peter Kung, 113-23. Oxford: Oxford University Press. Woleński, Jan. 2016. "Logic in the Light of Cognitive Science." Studies in Logic, Grammar and Rhetoric 48(61). 87-101.

Yablo, Stephen. 1993. "Is Conceivability a Guide to Possibility?” Philosophy and Phenomenological Research 53: 1-42. 